\title{
LICITAÇÃO COMO FERRAMENTA DE CONTROLE E TRANSPARÊNCIA NA ADMINISTRAÇÃO PÚBLICA
}

\author{
Lucas Oliveira Soura ${ }^{1}$ \\ Raiane Lima Silva Soares ${ }^{2}$ \\ Maria Madalena Soura dos Anjos Neta ${ }^{3}$
}

\begin{abstract}
RESUMO
A função do Estado é oferecer serviços como educação, saúde, segurança, dentre outros com qualidade, ou seja, é responsável por gerenciar os recursos do país e assegurar estes direitos à sociedade. Nesse sentido, percebe-se que a Administração Pública tem, por obrigação, atender as demandas de interesse coletivo, para tanto, utilizam a licitação. Para controlar o processo licitatório, criou-se a Lei 8.666/93, que rege este procedimento no âmbito federal, de forma geral, e a Lei 9.433/2005, que regulamenta, de forma específica, no Estado da Bahia. O presente artigo buscou analisar qual o modelo licitatório trouxe maior celeridade para a Universidade Estadual do Sudoeste da Bahia (UESB), e a transparência dos processos, no período de 2015 a 2016. Dessa forma, realizou-se um levantamento bibliográfico, tomando-se por base estudos de vários autores que discutem este tema, a fim de embasar a pesquisa. Utilizou-se trabalhos de Di Pietro (2010), Meirelles, Burle Filho e Burle (2016), Nascimento (2016), Mello (2009), entre outros. A pesquisa é caracterizada como exploratória-descritiva, quantitativa, além de utilizar a pesquisa documental, a observação não participante e a não estruturada como instrumentos de coleta de dados. Percebeu-se que o pregão eletrônico, presencial e carta convite, foram as mais céleres. Quanto à transparência, notou-se que a universidade divulga os certames no Diário Oficial do Estado e em jornais de grande circulação, conforme estabelece a legislação. Porém, a UESB apresenta falhas nesta etapa, pois, em seu portal da transparência, encontrou-se incongruências de dados, visto que a plataforma apresentou duplicidade em licitações, além de não conter informações completas.
\end{abstract}

Palavras-chave: Administração Pública. Celeridade. Licitação. Transparência.

\section{BIDDING AS A TOOL FOR CONTROL AND TRANSPARENCY IN THE PUBLIC ADMINISTRATION}

\begin{abstract}
The function of the State is to offer services such as education, health and safety, among others with quality, that is, it is responsible for managing the country's resources and ensuring these rights to society. In this sense, it is perceived that the Public Administration has, by obligation, to meet the demands of collective interest, for that, they use the bidding. In order to control the bidding process, Law 8.666/93 was created, which governs this procedure at the federal level, in general, and Law 9.433 / 2005, which regulates, specifically, the state of Bahia. The present article sought to analyze which bidding model brought more speed to the State University of Southwest of Bahia, and the transparency of the processes, in the period of 2015 and 2016. In this way, a bibliographic survey was carried out, based on studies of several authors who discuss this topic in order to base the research. It was used the works of Di Pietro (2010), Meirelles, Burle Filho and Burle (2016), Nascimento (2016), Mello (2009), among others. The research is characterized as exploratory-descriptive, quantitative, in addition to using documentary research, non-participant observation and unstructured observation as instruments of data collection. It was noticed that the electronic, face-to-face and invitation letter were the fastest. As for transparency, it was noted that the university disseminates the events in the Official State Gazette and in newspapers of great circulation, according to the legislation. However, the UESB has flaws in this stage, because, in its transparency portal, there were data inconsistencies, since the platform presented duplication in bids, besides not containing complete information.
\end{abstract}

Keywords: Public Administration. Celerity. Bidding. Transparency.

\footnotetext{
${ }^{1}$ Graduado em Administração pela Universidade Estadual do Sudoeste da Bahia (UESB). E-mail: lucas.olisou@hotmail.com

${ }^{2}$ Graduada em Administração pela Universidade Estadual do Sudoeste da Bahia (UESB). E-mail: raianeuesb@yahoo.com

${ }^{3}$ Professora Adjunta do Departamento de Ciências Sociais Aplicadas (DCSA) da UESB. E-mail: madalena@uesb.edu.br
} 


\section{Introdução}

A corrupção está presente no mundo desde que a sociedade passou a conviver de forma agrupada e ter uma estrutura com sistemas que envolvem poderes. Esta prática ilícita se perpetuou em diversas gerações, a datar do império romano até a atualidade, portanto, evidencia-se que os mecanismos de fiscalização para evitar o ato são violados desde os governos autocráticos. Dessa forma, percebe-se que a desmoralização tem raiz milenar e que os fatos atuais são reflexos desse passado. Livianu (2014 apud MEIRA, 2016, p. 9) define este ato de deturpação como "toda e qualquer vantagem obtida pelos agentes públicos no exercício das funções que cause prejuízo aos bens, serviços e do interesse do Estado".

A questão da prática corrupta se manifesta no mundo nos setores privado e público. No Brasil, esse termo teve grande destaque nos últimos anos em razão dos inúmeros escândalos políticos que são divulgados pelas redes de telecomunicação nacional e internacional. Logo, como forma de minimizar a desordem na Administração Pública, fortalecer a democracia e ter um controle social, surge a transparência pública. A exteriorização das ações do governo aos brasileiros visa publicar as despesas dos órgãos e entidades, como também informar orçamentos, processos licitatórios, contratos e convênios e até gastos com diárias e passagens.

Instituições, como as universidades públicas, estão inseridas nesse contexto de transparência e tem grande relevância no desenvolvimento do país, desse modo, elas são sujeitas a prestarem contas e torná-las públicas. Faz-se necessário entender como procede a clareza nestas instituições, desde o procedimento de compra, a licitação, até a utilização dos recursos, a fim de detectar alguma anormalidade ou apenas como forma de conhecimento.

Os procedimentos de licitação devem ser realizados em sequência lógica a partir de duas fases distintas: externa e interna. A primeira associa-se com a publicação do edital ou envio da carta convite, quando necessário. Na segunda, efetuam-se levantamentos de preços com intuito de presumir os custos e definir a modalidade que será usada, que pode ser: concorrência, tomada de preço, convite, concurso, leilão e pregão eletrônico. Juntamente com estas modalidades, são utilizados critérios que auxiliam a avaliação da escolha, como o menor preço, melhor técnica, técnica e preço e maior lance ou oferta.

O então Presidente Itamar Franco sancionou a Lei 8.666/93, onde estabelece normas gerais sobre licitações e contratos administrativos referentes a serviços, obras, aquisição de materiais e suas alocações na União, nos Estados, no Distrito Federal e nos Municípios. O Governo do Estado da Bahia utilizou esta lei, juntamente com a Lei do pregão 10.520/2002, como parâmetro para a criação da sua própria legislação quanto ao processo de compras para órgãos públicos. Posto isso, criou-se a Lei Estadual 9.433/2005, para abranger todas as modalidades e com algumas adaptações, a fim de tornar o processo mais eficaz. 


\section{Administração Pública}

O Estado é responsável por garantir o desenvolvimento da saúde, da educação, da moradia, da segurança e vários outros direitos para a sociedade. Dessa forma, a Administração Pública surge nesse contexto para assegurar os interesses coletivos com planejamento, organização, liderança e controle. Bachtold (2012, p. 31) salienta que "a palavra administração vem do latim ad (direção) e minister (obediência), ou seja, o administrador dirige obedecendo à vontade de quem o contratou". A partir deste conceito, o autor afirma que o administrador público tem como papel coordenar suas atividades para atender à necessidade da população. Tal afirmação pode ser complementada por Araújo (2014, p. 7), no qual aponta que a "Administração Pública pode ser definida como conjunto harmônico formado por entidades, órgãos e agentes públicos, destinado a exercer as atividades inerentes ao Estado e aos seus fins".

O termo Administração Pública pode ser expresso a partir de dois sentidos: subjetivo e objetivo. Di Pietro (2010, p. 49) coloca essas interpretações da seguinte forma:

a) em sentido subjetivo, formal ou orgânico, ela designa os entes que exercem a atividade administrativa; compreende pessoas jurídicas, órgãos e agentes públicos incumbidos de exercer uma das funções em que se triparte a atividade estatal: a função administrativa; b) em sentido objetivo, material ou funcional, ela designa a natureza da atividade exercida pelos referidos entes; nesse sentido, a administração pública é a própria função administrativa que incumbe, predominantemente ao Poder Executivo.

No âmbito nacional, a Administração Pública se divide em três esferas: Federal, Estadual e Municipal e estruturada de forma hierárquica. A primeira refere-se à coordenação de atividades que são realizadas pela União. A segunda diz respeito ao gerenciamento das operações desenvolvidas pelos Estados e o Distrito Federal. Por fim, a terceira é responsável por comandar os poderes Legislativo, Executivo e Judiciário.

\section{Transparência Pública}

O Art. $5^{\circ}$, inciso XXXIII, da Constituição Federal/88, assegura que todos devem ter acesso a relatórios dos setores públicos, ora de interesse particular ou coletivo. Por se tratar de questão pública, a disponibilização da transparência é vista como um direito dos indivíduos. A clareza dessas informações é posta como uma explanação no que tange o cenário da política e da economia. Souza et al. (2009 apud GUADAGNIN, 2011, p. 4) afirma que a transparência

[...] tem como desígnio impedir ações impróprias e eventuais, como o uso indevido dos bens públicos, por parte dos governantes e administradores. Alargando o acesso dos cidadãos as informações públicas, em todas as esferas, a fim de edificação de um país mais democrático, onde todos os segmentos da sociedade possam desempenhar 
com êxito o controle social, ajudando na efetivação de uma gestão mais eficaz e eficiente.

Dentro da Administração Pública, a transparência é concretizada por meio de consultorias e sessões acessíveis, referendos, plebiscitos, bem como notificações e publicações que visam a eficácia, legitimidade, validade dos atos administrativos, controle e fiscalização das contas públicas. Logo, Gruman (2012), ao analisar a transparência como um princípio do gerenciamento fiscal, afirma que este antecede fatores como publicidade e entendimento das informações. Isto se torna plausível, uma vez que o ato de apenas expor dados, sem compreensibilidade, não se caracteriza transparência para a sociedade. Gruman (2012, p. 103) ainda ressalta que:

Prover o cidadão de informações públicas é necessário, mas não suficiente, devendo o Estado estimulá-lo à participação ativa na tomada de decisões e na formulação de políticas, incluindo a própria construção da informação pública. Trata-se, portanto, de estabelecer um diálogo com a sociedade civil numa nova maneira de gerir a coisa pública, o que se chama de gestão compartilhada.

Em 18 de novembro de 2011, a então Presidente Dilma Rousseff sancionou a Lei n ${ }^{\circ}$ 12.527/2011, que visa regulamentar o acesso aos dados referentes à União, Estados, Distrito Federal e Municípios. Além disso, o Art. $2^{\circ}$ da lei frisa que a aplicação desta cabe também a "[...] entidades privadas sem fins lucrativos que recebam, para realização de ações de interesse público, recursos públicos diretamente do orçamento ou mediante subvenções sociais, contrato de gestão, termo de parceria, convênios, acordos, ajustes ou outros instrumentos congêneres”.

\section{Licitação Pública}

A Administração Pública é responsável por atender as necessidades da sociedade, para tanto, como não é capaz de satisfazer todas as demandas por conta própria, busca-se comprar serviços e produtos de terceiros. As contratações que são firmadas com as instituições públicas são decorrentes de processos de licitação, um procedimento administrativo rigoroso que visa selecionar as empresas que trarão mais benefícios, a exemplo do baixo custo para o poder público, a partir de fases interna e externa.

Para Carvalho Filho (2014 apud NASCIMENTO, 2016, p. 11), a licitação é um

procedimento administrativo vinculado por meio do qual os entes da Administração pública e aqueles por ela controlados selecionam a melhor proposta entre as oferecidas pelos vários interessados, com dois objetivos - a celebração de contrato, ou obtenção do melhor trabalho técnico, artístico ou científico. 
A licitação surge como um instrumento para os gestores públicos com a finalidade de apresentar transparência e eficiência nas aquisições feitas pelo governo. Nesse sentido, na visão de Meirelles, Burle Filho e Burle (2016), todo esse processo estabelece atos tanto para as instituições quanto para os licitantes, a fim de proporcionar igualdade perante os interessados em licitar, bem como trabalhar com o máximo grau de eficiência, juntamente com a moralidade, haja vista que o procedimento é considerado como uma competição. Logo, a licitação é posta como

Certame que as entidades governamentais devem promover e no qual abrem disputa ente os interessados em com elas travar determinadas relações de conteúdo patrimonial, para escolher a proposta mais vantajosa às conveniências públicas. Estriba-se na ideia de competição, a ser travada economicamente entre os que preencham os atributos e aptidões necessários ao bom cumprimento das obrigações que se propõem assumir (MELLO, 2009, p. 517).

No âmbito nacional, segundo Otero (2012), os meios de licitação surgiram em meados de 1860, a partir do Decreto 2.926/1862, com regulamentação de aquisições de serviços para o Ministério da Agricultura, Comércio e Obras Públicas. Após esse início, demais Decretos e Decretos-Lei foram criados com o intuito de tratar sobre licitação no Poder Público.

Em 1993 foi aprovada a Lei 8.666/93 pelo então Presidente Itamar Franco, com a proposta de designar regimentos para a execução de licitação e contratos administrativos tanto para a arrematação de produtos quanto para a contratação de serviços para satisfazer os poderes públicos e, consequentemente, a sociedade. A lei garante que as três esferas, Federal, Estadual e Municipal, devem acompanhar as diretrizes impostas, como as instituições com administração direta e indireta, empresas, autarquias e fundações públicas, bem como as sociedades mistas.

A legislação é posta como um fator que contribui na burocratização das compras e contratações públicas. Dessa forma, Pimenta (1998, p. 15) a coloca como obstáculo para o processo de melhoria na gestão de compras das entidades públicas, em razão do demasiado grau de formalidade e uniformidade e que gera uma "demora excessiva para a realização de qualquer processo de compra além de se apresentar como uma forma de controle burocrático de eficácia duvidosa”.

A Lei 8.666/93 evidencia duas formas para a não utilização dos meios licitatórios, um referente à dispensa e outro quanto à inexigibilidade. A primeira é expressa no Art. 17, inciso I, onde fica firmado que, quando se referir sobre imóveis, após avaliação e autorização do poder legislativo, será dispensada a licitação. Não obstante, os casos devem estar relacionados com um acordo entre credor e devedor; doação ou venda entre órgãos públicos de qualquer esfera; investidura ou com locação de imóveis residenciais com até $250 \mathrm{~m}^{2}$ para atender interesses da sociedade. Ao se tratar de bens móveis, o inciso II afirma que as dispensas estão associadas com doação, desde que seja para interesse social; permuta entre as entidades; vendas de ações ou títulos e bens produzidos pelos próprios órgãos. 
A segunda condição é sustentada no Art. 25, em que aponta a falta de competição e caracteriza a inexigibilidade. Em especial, fica inexigível a licitação para a compra de materiais que são supridos por fornecedores exclusivos, em que deve ser ignorada qualquer preferência quanto a marcas. Além disso, a contratação de serviços técnicos como perícias, planejamentos e projetos básicos, restauração de obras de artes ou bens com valores históricos, dentre outros.

Di Pietro (2010, p. 365) coloca a discrepância entre tais condições da seguinte forma:

[...] na dispensa, há possibilidade de competição que justifique a licitação; de modo que a lei faculta a dispensa, que fica inserida na competência discricionária da Administração. Nos casos de inexigibilidade, não há possibilidade de competição, porque só existe um objeto ou uma pessoa que atenda às necessidades da Administração; a licitação é, portanto, inviável.

A Constituição Federal de 1988, em seu Art. 22, firma o ato da União ter o poder de legislar, conforme exposto no inciso XXVII, que garante criar leis quanto ao processo de licitação e contratação para os setores públicos como, Autarquias, União, Estados, Municípios e entidades públicas que apresentam economia mista. Por meio desta abertura na Carta Magna, o Estado da Bahia criou a sua própria lei sobre o procedimento de aquisição de produtos e serviços, a Lei 9.433/2005.

A referida lei traz em seu contexto todas as modalidades licitatórias encontradas na Lei Federal 8.666/93 como, concorrência, tomada de preços, convite, concurso e leilão, bem como o pregão que é expresso na Lei 10.520/2002. Numa breve análise comparativa, nota-se que a lei estadual se encontra mais completa, haja vista que abrange todas as modalidades em uma única legislação. Os dois primeiros modelos caminham para a mesma finalidade: contratar serviços, obras, bem como fornecimento de matérias-primas. As duas últimas apresentam propósitos diferentes, pois uma se refere à escolha de partes intelectuais e a outra se associa com vendas mediante lances feitos pelos interessados. Quanto ao pregão, este é destinado para a aquisição de bens e serviços que são considerados comuns e previstos na lei.

\section{Processo de Compras da Universidade Estadual do Sudoeste da Bahia (UESB)}

A UESB, em sua estrutura organizacional tem a Pró-Reitoria de Administração (PROAD), que visa gerenciar as atividades administrativas a fim de satisfazer as necessidades impostas pela comunidade universitária. Desse modo, juntamente com o apoio das Gerências e Assessorias, esta próreitoria preza pela manutenção, crescimento, desenvolvimento e modernização da Instituição.

O processo de aquisições da UESB é administrado pela Gerência Administrativa (GAD) da instituição, que visa "gerenciar as aquisições da Instituição em relação a materiais de consumos, permanentes, serviços, obras e reformas" (UESB, 2017). Além disso, a GAD tem como papel acompanhar as atividades de licitação, materiais e patrimônio, relação com os fornecedores e compras. 
No setor de compras, o procedimento de aquisição é guiado pelo Subgerente de Compras, que é responsável pelo trâmite processual para que o item demandado seja adquirido, caso seja por compra direta. Essa aquisição realizada diretamente pela UESB, sem processo licitatório, leva em consideração o valor do objeto, ou seja, montante inferior a $\mathrm{R} \$ 8.000,00$ (oito mil reais) para materiais de consumo e permanente, $R \$ 15.000,00$ (quinze mil reais) para serviços e obras de engenharia, dispensa-se a licitação.

O primeiro passo desse processo refere-se à demanda feita por determinado setor da UESB, a partir do preenchimento do formulário de solicitação de compras ou serviços no Sistema Integrado de Material, Patrimônio e Serviço (SIMPAS). Este mecanismo foi adotado pela Instituição em 2012, a fim de atender às exigências do Tribunal de Contas do Estado (TCE-BA), que visa aperfeiçoar e tornar prática tal atividade. Depois do recebimento desse pedido, a coordenação verifica o Sistema de Registro de Preços (SRP), ou seja, de uma ferramenta instituída pelo poder público, analisa se tem cadastro de preços para os itens, tanto para produtos quanto para prestação de serviços.

Caso o item demandado esteja no registro de preço, este é adquirido de forma direta, após a liberação da Secretaria de Administração do Estado da Bahia (SAEB). Após o envio do pedido de liberação, aguarda-se por volta de sete dias úteis para a anuência desta solicitação. Entretanto, conforme informações do setor de compras da UESB, caso o processo apresente um montante acima de R\$ 80.000,00 (oitenta mil reais), este deverá será enviado para Salvador para avaliação, que pode levar cerca de 60 (sessenta) dias. Se não houver registro neste sistema, realiza-se uma terceira etapa: a cotação. Logo, os responsáveis têm como incumbência pesquisar diferentes preços do produto/serviço de, no mínimo, três empresas.

\section{Metodologia}

O presente artigo é uma pesquisa exploratória-descritiva, posto que, todo o procedimento licitatório da UESB foi explorado e também foram descritas as modalidades que trazem mais benefícios para a instituição, em relação ao aspecto celeridade, a partir da análise do tempo dos certames, bem como a identificação das formas que a UESB utiliza para tornar esses processos transparentes para a sociedade e para os órgãos fiscalizadores. Além disso, o estudo possui caráter quantitativo, uma vez que foi quantificado o número de licitações realizadas no período de 2015/2016, e verificou-se a duração dos processos licitatórios neste intervalo de tempo. A escolha do objeto desta pesquisa foi contemplada em um estudo de caso único na Universidade Estadual do Sudoeste da Bahia (UESB).

Para a elaboração deste estudo utilizou-se documentos que apresentam as formas de compras para órgãos públicos como a Lei 8.666/93, Lei 10.520/2002, Lei 9.433/2005, dentre outras leis e decretos que serviram para o embasamento do contexto. Além dessas legislações, a Constituição Federal de 1988, Revista do Tribunal de Contas da União e relatórios da Pró-Reitoria de Administração, 
contribuíram para a construção da pesquisa. As observações não estruturadas e não participantes também foram utilizadas como instrumento de coleta.

\section{Licitações da UESB}

Os processos de licitação da UESB analisados foram dos exercícios de 2015 e 2016, os quais obtiveram um total de 210 certames. Os dados que serão demonstrados no presente estudo se tratam dos campi de Vitória da Conquista e Itapetinga, visto que o campus de Itapetinga não possui comissão de licitação instalada.

Em 2015, a UESB realizou 99 certames para atender dois campi, Vitória da Conquista e Itapetinga, para a aquisição de material de consumo e/ou permanente, prestação de serviços, concessão de uso e alienação. Foram formalizadas 1 licitação para alienação, 34 licitações para aquisição de material de consumo, 4 para material de consumo e permanente, 22 para material permanente, 3 para concessão de uso e 35 para prestação de serviço. Dessa forma, percebe-se que o grande consumo na UESB em 2015, em relação aos certames, foi concentrado na área de prestação de serviços que, neste ano, foi representada pela contratação de empresas que ofereceram as seguintes atividades: confecção de becas, carimbos e cercas, além da reforma dos prédios da universidade, reprografia, transporte rodoviário, fornecimento de refeições, coleta de lixo e outros.

Em seguida, destacam-se as compras de materiais de consumo como, reagentes para laboratórios, equipamentos para expedientes, ração para animais, materiais de construção, hospitalar, odontológicos, apicultura e elétrico, tal como cartuchos para impressoras. Além destes, o consumo de material permanente também apresenta suas demandas, uma vez que está relacionado com itens do acervo bibliográfico da instituição, informática e compra de carros para uso da universidade. Os processos de licitação ainda foram utilizados para a aquisição de bens de consumo e permanente de forma paralela. A UESB utilizou estes procedimentos para a alienação de semoventes, ou seja, a venda de caprinos para terceiros, conforme estabelecido na legislação. Por fim, foram oferecidas áreas físicas da universidade (quiosques), pela concessão de uso, para venda de lanches e recarga de cartão escolar dos estudantes, para atender a demanda da comunidade universitária.

Ao analisar o ano de 2016, elencam-se 111 certames, no qual 3 estão voltados para a alienação de semoventes, 47 para aquisição de material de consumo, 6 visam atender a demanda quanto a aquisição de material de consumo e permanente de forma simultânea, 36 para permanente e apenas 19 para prestação de serviços.

Logo, ao fazer uma analogia entre os dois anos, verifica-se que houve grande variância nas demandas, por parte dos solicitantes. Em relação à alienação de caprinos e ovinos, evidencia um aumento de 66,67\% na realização desta atividade, visto que 2015 ocorreu apenas uma transferência, 
entretanto, em 2016 foram executadas três alienações. O objeto caracterizado pelas aquisições de material de consumo registrou uma alavancagem de $27,66 \%$, resultante da grande demanda de itens referente a este objeto. A universidade também realizou procedimentos licitatórios para adquirir, de forma simultânea, material de consumo e permanente, neste ponto, a pesquisa constatou uma elevação de 33,3\%. Na compra de materiais de natureza permanente evidenciou-se um aumento de 38,89\%. No exercício de 2015 houve três procedimentos para a concessão de uso de áreas da UESB para utilizar como ponto de vendas de alimentos para a comunidade da instituição, entretanto, no seguinte ano, não foi registrada nenhuma atividade desse caráter.

Por fim, analisou-se o número de certames, cujo objeto é a prestação de serviços para atender às demandas da UESB. Este foi o único que apresentou uma queda entre os dois períodos estudados, posto que em 2015 foram 35 acordos firmados para contratar determinados serviços; já em 2016, apenas 19 atividades referentes a este objeto, o que resulta num declínio de 84,21\%.

A presente pesquisa também elencou as modalidades utilizadas nos procedimentos de licitação na autarquia. A amostra do ano de 2015 revelou a assídua presença do pregão nos certames, no qual 60 foram realizados de forma eletrônica e 13 de maneira presencial. A carta convite foi a segunda mais utilizada, com o total de 21 processos. Em seguida, aparece a concorrência com 3 e, por fim, as modalidades leilão e tomada de preços que registraram apenas 1 cada.

O pregão se mostrou mais constante no ano de 2016, visto que houve um aumento de 23,96\% em comparação ao ano anterior. Grande parte desse resultado é representado pelos 87 processos da instituição ocorridos eletronicamente e apenas 9 que foram realizados de forma presencial. Além desta modalidade, a carta convite marcou um total de 12 licitações e o leilão. Nesse referido tempo não foram apontados certames que atendessem os critérios da ampla concorrência e tomada de preços.

Logo, nota-se o claro domínio da modalidade pregão em ambos os anos nos processos de licitação da UESB, com participação totalizada em 70\%, ao considerar todos 210 certames analisados. A versão eletrônica desse modelo se mostrou bastante evidenciada na pesquisa, isso ocorre em razão da simplicidade, economicidade, celeridade, transparência e pouca burocratização.

A celeridade dos certames também foi um fator estudado nesta pesquisa, a fim de identificar a modalidade mais célere dentro da UESB. Ao considerar, nesta pesquisa, que o tempo de duração para a conclusão de um processo licitatório é de 30 dias, percebe-se que a UESB apresenta um total de 69,52\% de certames céleres referentes aos 210 estudados nos anos de 2015 e 2016. Logo, ao analisar de forma separada, nota-se que em 2015, das 99 licitações realizadas, cerca de 73,74\% foram finalizadas em tempo hábil. Já em 2016, em torno de 65,76\% foram concluídas em um período consideravelmente rápido. Ressalta-se que dentro destes números de processos concluídos estão inclusos os que foram homologados, revogados e anulados. 
No primeiro ano estudado, a modalidade pregão eletrônico foi a que mais apresentou celeridade em seu desenvolvimento, visto que dos 73 certames, 36 correspondem a esta categoria. Esta ainda mostrou maior representatividade no exercício posterior, em que o número de pregões eletrônicos alcançou um total de 55 licitações das 111 que foram analisadas no ano de 2016.

O resultado de grande destaque desta modalidade se deve pela inversão de fases que ocorre nos processos que seguem a Lei $9.433 / 2005$, visto que primeiro realiza-se o julgamento das propostas, a classificação, e, posteriormente, a habilitação. Isso ocorre justamente para gerar mais rapidez nos procedimentos, uma vez que será necessário analisar os documentos apenas dos que foram classificados, o que ocorre de maneira diferente nos processos da Lei 8.666/93, que habilitam todos os participantes e depois começa a fase de julgamento.

Além disso, existe outro ponto que contribui para agilidade desse modelo também na fase externa: o edital. Este deve ser publicado com o prazo mínimo de 8 dias úteis antes do recebimento das propostas. A celeridade é vista igualmente na fase de recursos, posto que, caso seja manifestada a intenção de recorrer por parte dos outros participantes, os quais terão um prazo de 3 dias úteis para apresentar a documentação no sistema. Este mesmo interesse de entrar com recurso tem o prazo de 5 dias úteis nas demais modalidades, segundo a Lei 9.433/2005.

O segundo modelo licitatório que também se encontra dentro dos parâmetros de celeridades estabelecidos neste estudo é a carta convite. Das 73 licitações consideradas céleres no ano de 2015, 20 pertencem a esta modalidade. Ao considerar o mesmo número de processos estudados no ano seguinte, aponta-se que houve uma queda na quantidade de licitações ágeis neste modelo, dado que apenas 12 foram carta convite.

A carta convite tem como particularidade o fato de poder escolher os interessados para participar do processo, a partir dos critérios de honestidade e credibilidade, e são escolhidos no mínimo três participantes para compor esse procedimento licitatório. É válido frisar que este modelo apresenta restrições em relação aos valores estimados, visto que só servem para obras e serviços, cujo valor chegue até cento e cinquenta mil reais, e quanto às compras e serviços, o valor não pode ultrapassar R\$ $80.000,00$ (oitenta mil reais).

A grande característica da carta convite que promove a alta presteza se diz respeito a não utilização de edital, pois a própria carta é identificada como o instrumento convocatório para o certame. A simplicidade desta modalidade se encontra até no ato de divulgação, já que tem o prazo mínimo de 5 dias, o menor tempo de todas as modalidades, e pode ser fixada em qualquer mural no qual o público interessado tenha acesso com facilidade.

Por fim, o pregão presencial foi a terceira modalidade que demonstrou rapidez no desenvolvimento dos processos licitatórios. No geral, foram apenas 16, do qual 12 aconteceram no ano de 2015 e as outras 4 no ano seguinte. Ao analisar a participação da carta convite como instrumento 
célere, nota que ela representa apenas $11,51 \%$ de todos que foram finalizados em tempo hábil. Ou seja, dos 139 certames postos nesta classificação, somente 16 são referentes a este modelo.

\section{Transparência e Fiscalização nas Licitações da UESB}

No âmbito da universidade esse processo de transparência, em relação à divulgação dos certames, é feito pela Empresa Gráfica da Bahia (EGBA), uma organização pública com personalidade jurídica de direito privado, patrimônio próprio, autonomia administrativa e financeira e capital exclusivo do Estado, conforme exposto no Art.1, da Lei 3.037/72. Segundo o Presidente da Comissão Permanente de Licitação, a instituição firmou contrato com a EGBA para que esta tivesse como função principal a publicação de atos oficiais da UESB, inclusive a divulgação dos atos relativos aos procedimentos licitatórios no Caderno Especial de Licitações do Diário Oficial do Estado.

Outra forma de transparência nesses processos é a divulgação no portal do Governo Comprasnet.ba, que tem como função realizar processos eletrônicos de compras, bem como disponibilizar informações sobre as licitações e contratações que são firmadas pelo governo. Este sistema governamental visa informar a programação de todos os certames que serão realizados no Estado para organizações interessadas em ser fornecedoras da UESB. Nesse sentido, esta ação é posta como forma de garantir que as licitações sejam transparentes, uma vez que buscará contar com o maior número de concorrentes em cumprimento dos princípios da Administração Pública: Legalidade, Impessoalidade, Moralidade, Publicidade e Igualdade.

Ao se tratar de licitação de grande vulto, essa divulgação precisa ser feita em um jornal de grande circulação. Nesta situação, a UESB tem contrato com outra empresa, a Gibbor Brasil Publicidade e Propaganda, que faz essa publicação e divulgação em jornais com abrangência preponderante nas regiões Nordeste, Sudeste e Centro-oeste, e nas capitais da Bahia e Minas Gerais. Atualmente, segundo o Gerente Administrativo, a empresa realiza essa transparência no jornal Valor Econômico.

Por fim, a UESB ainda divulga os seus processos licitatórios no próprio site da instituição como forma de abranger um público ainda maior para participar dos certames, bem como torná-los públicos. Neste site constam as licitações de 2004 até o ano de 2017, com dados sobre o campus que realizou o processo, a modalidade, data da abertura, situação, tipo de licitação e objeto.

Todas essas questões de formalização, execução e transparência dos certames devem ser fiscalizadas, a fim de assegurar a integridade do procedimento. Essa fiscalização ocorre de duas formas: interna e externa. A primeira é feita pelo fiscal direto, ou seja, aquele que solicitou a aquisição do bem ou serviço; pela Comissão de Fiscalização e Acompanhamento de Contratos, que analisa o trâmite do processo durante a elaboração do edital e após sua publicação; pela Procuradoria Jurídica (PJ) da 
universidade, uma vez que para a divulgação deste edital é necessário um parecer da PJ. Quanto à auditoria externa, esta é feita pelo Tribunal de Contas do Estado da Bahia. De acordo com o Gerente Administrativo, os apontamentos feitos pelo TCE foram apenas para reforçar e aprimorar os processos, uma vez que a atual gestão da UESB busca não apresentar falhas nas licitações.

\section{Considerações Finais}

O estudo mostrou que 146 licitações de 210, ou seja, cerca de 69,52\% ocorreram de forma célere. A partir deste resultado, constatou-se que a primeira modalidade que se mostrou rápida foi o pregão eletrônico, que teve bastante representatividade tanto em 2015 quanto em 2016. A carta convite e o pregão presencial foram as outras modalidades que apresentaram celeridade em seus procedimentos. Esta agilidade processual ocorre em razão das características da legislação estadual, uma vez que esta proporciona uma economicidade no tempo, pois é adotada uma inversão de fases que gera esse benefício. A Lei 9.433/2005, primeiro faz o julgamento das propostas, só depois realiza a habilitação, por meio dessa inversão, em relação à Lei Federal 8.666/93, a autarquia não tem dispêndio de tempo, posto que só analisará os documentos de habilitação dos vencedores.

No caso do pregão, tanto presencial quanto eletrônico, a celeridade é vista na publicação do edital, uma vez que tem o prazo curto para realizar este feito. Quanto à carta convite, a praticidade em não utilizar o instrumento convocatório, como ocorre nas outras modalidades, evita a morosidade nos procedimentos. Entretanto, a pesquisa registrou que tais modelos também estão presentes em processos que apresentaram alto grau de morosidade, dessa forma, percebe-se que as modalidades em si não são ferramentas únicas para identificar a celeridade de um processo licitatório.

A pesquisa mostrou que a Universidade Estadual do Sudoeste da Bahia (UESB) torna os processos transparentes por intermédio da Empresa Gráfica da Bahia (EGBA), que é responsável por publicá-los no Diário Oficial do Estado da Bahia e por outra empresa, a Gibbor, que publica em jornais nacionais. A UESB também realiza essa publicação na página da Comprasnet e na própria plataforma da instituição. Quanto às informações contidas no site da universidade, esta página de transparência apresentou incongruências de dados, o que fere a Lei de Acesso à Informação (LAI), no qual afirma que o Estado deve oferecer informações de forma transparente, clara e com linguagem de fácil compreensão.

Esta incongruência é resultante da duplicidade de licitações contidas neste portal, uma vez que, ao analisar as informações, percebeu-se que muitos certames continham informações repetidas, ou seja, foram registradas licitações mais de uma vez, neste site. Outro ponto negativo da plataforma da UESB é o fato de não ter dados completos, uma vez que não mostra a data que o certame se encerrou, muito menos o nome da empresa vencedora. 


\section{Referências}

ARAÚJO, S. B. Evolução da administração pública no Brasil focando o princípio da eficiência. 2014. 22 f. Trabalho de Conclusão de Curso (Graduação) - Universidade Estadual da Paraíba, Campina Grande, 2014. Disponível em: <http://dspace.bc.uepb.edu.br/jspui/bitstream/123456789/8460/1/PDF-Sebastião Brito de Araújo.pdf>. Acesso em: 17 abr. 2017.

BACHTOLD, C. Noções de administração pública. Instituto Federal de Educação, Ciência e Tecnologia, Paraná, 2012. Disponível em:

$<$ http:/ /ead.ifap.edu.br/netsys/public/livros/Livros $\% 20$ Curso $\% 20$ Servi $\% C 3 \%$ A7os $\% 20 \mathrm{P} \% \mathrm{C} 3 \%$ BAblicos/M $\%$ C3\%B3dulo $\% 20 I / C a p a \% 20$ Nocoes $\% 20$ Administracao $\% 20$ Publica_IFAP/Livro $\% 20$ Nocoes $\% 20$ Administracao\%20Publica.pdf>. Acesso em: 19 abr. 2017.

BAHIA. Lei n. 9.433, de 01 de março de 2005. Dispõe sobre as licitações e contratos administrativos pertinentes a obras, serviços, compras, alienações e locações no âmbito dos Poderes do Estado da Bahia e dá outras providências. Diário Oficial do Estado da Bahia. Disponível em:

<http://www.legislabahia.ba.gov.br/verdoc.php?id=63892>. Acesso em: 12 ago. 2017.

BRASIL. Constituição (1988). Constituição da República Federativa do Brasil. Brasília, DF: Senado, 1988.

. Decreto n. 2.926, de 14 de maio de 1862. Aprova o Regulamento para as arrematações dos serviços a cargo do Ministerio da Agricultura, Comércio e Obras Públicas. Coleção de Leis do Império do Brasil. Disponível em:

$<$ http://legis.senado.gov.br/legislacao/ListaPublicacoes.action?id=75862\&tipoDocumento=DEC\&tip o'Texto $=$ PUB $>$. Acesso em: 05 maio 2017.

Lei n. 8.666, de 21 de junho de 1993. Regulamenta o art. 37, inciso XXI, da Constituição Federal, institui normas para licitações e contratos da Administração Pública e dá outras providências. Diário Oficial da República Federativa do Brasil. Disponível em: <http://www.planalto.gov.br/ccivil_03/leis/L8666cons.htm>. Acesso em: 03 mar. 2017.

. Lei n. 10.520, de 17 de julho de 2002. Institui, no âmbito da União, Estados, Distrito Federal e Municípios, nos termos do art. 37, inciso XXI, da Constituição Federal, modalidade de licitação denominada pregão, para aquisição de bens e serviços comuns, e dá outras providências. Diário Oficial da República Federativa do Brasil. Disponível em:

<http://www.planalto.gov.br/ccivil_03/leis/2002/110520.htm>. Acesso em: 05 mar. 2017.

. Lei n. 12.527, de 18 de novembro de 2011. Regula o acesso a informações previsto no inciso XXXIII do art. $5^{\circ}$, no inciso II do $\int 3^{\circ}$ do art. 37 e no $\$ 2^{\circ}$ do art. 216 da Constituição Federal; altera a Lei $\mathrm{n}^{\circ}$ 8.112, de 11 de dezembro de 1990; revoga a Lei $\mathrm{n}^{\circ}$ 11.111, de 5 de maio de 2005, e dispositivos da Lei no 8.159, de 8 de janeiro de 1991; e dá outras providências. Diário Oficial da República Federativa do Brasil. Disponível em: < http://www.planalto.gov.br/ccivil_03/_ato2011-2014/2011/lei/112527.htm>. Acesso em: 30 ago. 2017.

DI PIETRO, M. S. Z. Direito administrativo. 23. ed. São Paulo: Atlas, 2010.

GRUMAN, M. Lei de Acesso a Informação: notas e um breve exemplo. Revista Debates, Porto Alegre, v. 6, n. 3, p. 97-108, set./dez. 2012. Disponível em:

<http://www.seer.ufrgs.br/debates/article/download/34229/23345>. Acesso em: 22 set. 2017. 
GUADAGNIN, A. A transparência na gestão pública: uma análise da sua concretização em Porto Alegre, Canoas e Novo Hamburgo. 2011. 21 f. Trabalho de Conclusão de Curso (Graduação) - Universidade Federal do Rio Grande do Sul, Porto Alegre, 2011. Disponível em:

<https://www.lume.ufrgs.br/bitstream/handle/10183/34888/000785026.pdf?seque>. Acesso em: 25 mar. 2017.

MEIRA, F. V. S. Controle de corrupção no Brasil, lei anticorrupção empresarial e sua regulamentação no estado do Espirito Santo. 2016. 52 f. Trabalho de Conclusão de Curso (Especialização) - Universidade de Brasília, Brasília, 2016. Disponível em:

<http://bdm.unb.br/bitstream/10483/16159/1/2016_FrancineVilhenadeSouzaMeira_tcc.pdf>. Acesso em: 29 mar. 2017.

MEIRELLES, H. L.; BURLE FILHO, J. E.; BURLE, C. R. Direito administrativo brasileiro. 47. ed. São Paulo: Malheiros, 2016.

MELLO, C. A. B. de. Curso de direito administrativo. 26. ed. São Paulo: Malheiros Editores, 2009.

NASCIMENTO, G. S. A. Licitação na Administração Pública: Regime Diferenciado de Contratações Públicas - RDC. 2016. 65 f. Trabalho de Conclusão de Curso (Graduação em Administração) Universidade de Brasília, Brasília, 2016. Disponível em:

<http://bdm.unb.br/bitstream/10483/13957/1/2016_GlaucoSoaresAlcantaraNascimento.pdf>. Acesso em: 24 mar. 2017.

OTERO, L. F. Licitações e contratos na administração pública. Maringá, 2012. 194 f. Disponível em: <http://www.ead.cesumar.br/moodle2009/lib/ead/arquivosApostilas/1490.pdf>. Acesso em: 07 abr. 2017.

PIMENTA, C. C. Desafios e oportunidades no setor de compras governamentais na América Latina e Caribe: o caso brasileiro. Brasília: ENAP, 1998. Disponível em:

<http://www.enap.gov.br/documents/586010/601535/25texto.pdf/bd92134f-22c2-4372-b307-

8b43ec7a716e>. Acesso em: 08 maio 2017.

UNIVERSIDADE ESTADUAL DO SUDOESTE DA BAHIA (UESB). Pró-Reitoria de Administração. Estrutura PROAD. Disponível em:

<http://www2.uesb.br/proreitorias/proad/?page_id=81>. Acesso em: 28 ago. 2017. 